\title{
Estimating the Influence of Extraction Method and Processing Location on Forest Harvesting Efficiency - A Categorical DEA Approach
}

\author{
Okey Francis Obi ${ }^{1} *$ (D), Rien Visser ${ }^{2}$ (iD) \\ ${ }^{1}$ Agricultural \& Bioresources Engineering Department, University of Nigeria, Nsukka, Nigeria. \\ ${ }^{2}$ New Zealand School of Forestry, University of Canterbury, Christchurch, New Zealand
}

\begin{abstract}
The increasing level of competition in the global forestry market demands that stakeholders continuously measure their performance with the aim of remaining competitive and profitable in the ever-changing wood market. This study applies categorical data envelopment analysis (DEA) methodology to the New Zealand forest harvesting sector. This methodology is able to account for ordinal non-discretionary variables in the DEA. The influence of $\log$ extraction method and processing location on the estimated efficiency scores were examined. To define the forest harvesting DEA production technology, three inputs (harvest area, average piece size, level of mechanization), one output (tons/scheduled hour) and one categorical non-discretionary variable with three levels were used. The categorical variables were defined by the level of difficulty as reported by harvest supervisors for specific forest harvesting operating environment. The study demonstrated the appropriateness of the categorical DEA approach in measuring performance in forest harvesting operations. It showed significant influence of timber extraction methods on the overall performance estimate, whereby grapple skidders at $58 \%$ had the highest mean efficiency score. While log processing locations showed no significant influence on the estimated performance, processing at the stump had the highest mean efficiency score.
\end{abstract}

Keywords: Forest harvesting, efficiency, operating environment, productivity

\section{Introduction}

Timber harvesting usually entail a number of methods including full-tree length, tree-length, and cut-to-length. The efficiency of various forest harvesting operations depend on a number of factors including the method utilized at the various work phases of timber harvesting (felling, processing, and extraction), productivity of the methods, and the operating environment (Obi and Visser, 2017a; Gerasimov and Sokolov, 2014; Obi and Visser, 2018). In addition, the choice of forest harvesting methods or techniques are often determined by environmental acceptability and economic gains for sustainable forest resources management (Stokes and Schilling, 1997; Marchi et al., 2018). Efficiency measurement with the aim of improving resource allocation and gaining competitive advantage has been a subject of interest for decision makers in the forest harvesting industry (Lebel, 1998; Obi and Visser, 2017b; Trzcianowska et al., 2019). This is mainly because stakeholders within the industry operate in a globally competitive market and are driven to be cost competitive and profitable in order to remain relevant in the ever-evolving market (Murphy and Cown, 2015).

The productivity of various forestry machines has been widely studied during logging operations to evaluate their productivity (Senturk et al., 2007; Alam et al., 2014; Kulak et al., 2017; Pajkoš et al., 2018; Lee et al., 2019).
However, the interplay between machine productivity and the nature of the operating environment (i.e., considering multiple environmental factors) are often overlooked. Such investigations could help identify the most productive method under different environmental conditions. Similar view had been expressed by Ghaffariyan et al. (2012) in studying the productivity of harvesters. Such studies would require optimized decision-making techniques using a range of predictive approaches (Rönnqvist et al., 2015; Brown et al., 2020).

Data envelopment analysis (DEA), a non-parametric approach, is able to estimate relative efficiency for a set of production units/systems based on multiple inputs/ output(s) with no assumption of the production function. This is also referred to as benchmarking being "the process of identifying the highest standards of excellence for products, services, or processes, and then making the improvements necessary to reach those standards commonly called best practices" (Bhutta and Huq, 1999). The measurement of production efficiency allows decision makers to identify differentials in performance among production units in the forest industry and also identify potential performance improvement avenues. Most efficiency analysis studies in forest harvesting within the literature have focused on establishing benchmarks for evaluating economic producers in the 
sector by estimating best production frontier (Lebel, 1998; Obi and Visser, 2017b). However, concerns expressed in recent studies is the explanation of factors responsible for differences in the efficiency of a pool of production units. For decision makers, useful application of efficiency studies is an understanding of conditions that might be responsible for inefficiencies among production units as well as identifying possible factors influencing productivity patterns.

This paper uses an economic production model to estimate the performance of forest harvesting operations categorized using the level of difficulty offered by the operating environment. To achieve this objective, Categorical Data Envelopment Analysis technique, a mathematical optimization model introduced by Banker and Morey (1986) is utilized. In addition, explanatory factors determining efficiency are also assessed by analyzing the influence of timber extraction method and $\log$ processing location on efficiency differentials among forest harvesting operations. The categorization of the harvesting operations based on the level of difficulty of the operating environment is important in obtaining unbiased performance estimates when comparing production units (Harrison et al., 2012).

\subsection{DEA and Categorical Variables}

DEA is one of the leading frontier efficiency techniques for estimating performance (or identifying best practice) of production units otherwise known as Decision Making Units (DMUs) (Kuah and Wong, 2011). The measurement of efficiency of DMUs is vital in assessing and managing the utilization of inputs in achieving desirable output levels (Golany and Roll, 1989). Best practice DMUs on the frontier identified by DEA are considered efficient and receive an efficiency score of 1 . Other DMUs not on the best practice frontier are considered inefficient and receive an efficiency score less than 1. Readers can refer to Cook and Seiford (2009) for a detailed review of DEA.

Standard DEA models (Charnes et al., 1978; Banker et al., 1984) assume that DMUs being assessed operate within homogeneous operating environments (Golany and Roll, 1989). However, in most business environments, the assumption of homogeneity is violated. As such various factors responsible for the differences in operating environment need to be included in the performance estimation process (Syrjänen, 2004; Obi and Visser, 2018). These factors are generally referred to as nondiscretionary, environmental or uncontrollable factors, and are often exogenously fixed (Daraio and Simar, 2007; Obi and Visser, 2017a). The inclusion of nondiscretionary factors in DEA, that is categorical groups, allows for the separation of DMUs performance from the circumstance in which the production activities were carried out thus providing an accurate interpretation of efficiency estimate (Muñiz, 2002). Banker and Morey (1986) provided a one-stage categorical DEA model for handling categorical (ordinal) non-discretionary variables. The model is such that a DMU is only compared to other DMUs in the same category. One limitation of the categorical DEA however, is the possibility of sample size bias due to often different number of DMUs in individual categorical groups. The categorical DEA approach is however able to provide reliable results for larger sample sizes (Harrison et al., 2012; Harrison and Rouse, 2014) as is the case in this study. The output-oriented variable returns to scale DEA model is used to estimate the efficiency of each forest harvesting operation category. For detailed information on categorical DEA, readers are referred to Banker and Morey (1986) and Harrison et al. (2012).

\section{Material and Methods \\ 2.1. Data and Production Factors}

The dataset used in this study consist of data on individual forest harvesting operations in New Zealand from the period 2009 to 2018. The database called Forest Growers Research (FGR) Benchmarking database is managed by the University of Canterbury and it provides detailed information on forest harvesting operating environment, forest stand, machinery and equipment usage, and harvesting systems (Visser, 2009). Entries are supplied by the forest management companies operating in various forest regions of New Zealand, whereby each entry is based on a unique, actual, recently completed harvest. On average, 150 entries are received each year; with a total over the 10-year period in excess of 1500 entries within the database. The FGR benchmarking database represents the only database of its kind in New Zealand. After screening the data for incomplete entries and outliers, a total of 1330 entries were utilized in the study.

In DEA studies, there is no standardized inputs and outputs for performance measurement of forest harvesting operations. As such, the selection of production factors in this study is based on availability of data, widely used factors in the literature and subjective judgement. The categorical DEA forest harvesting production technology is represented by three inputs, one output and a categorical variable. The DMUs are represented by individual forest harvesting operations utilizing certain inputs to achieve a certain level of production output. The inputs include mechanization index which represents the level of mechanization for an operation (i.e., ratio of number of machines to number of workers deployed), harvest area size (in hectares), and average stem/piece size (in tons). The output is represented by system productivity (in tons/SMH). The non-discretionary categorical variable is represented by the difficulty rating of the forest harvesting operating environment and it is categorized into three levels - 'easy', 'medium' and 'hard'. The difficulty of an operating environment is rated by the harvesting crew operating in the environment and the rating is arrived at by considering a number of uncontrollable factors 
hindering the smooth running of the harvest operation including terrain, indigenous forest reserves to work around, intermediate ridges, swamps, waterway crossing, and difficult soils.

\subsection{Statistical Analysis}

The Kruskal-Wallis test, which is a generalization of the Mann-Whitney test with more than two groups (Kruskal and Wallis, 1952), is used in order to statistically test the existence of a categorical effect on the estimated efficiency scores of the DMUs. The mean efficiency scores associated with different extraction methods and log processing location were compared statistically for significance of difference. This was to ascertain the influence of these factors on the estimated performance scores. In each case, the null hypothesis $\mathrm{H}_{0}$ (there is no difference in the mean efficiency scores) was tested against the alternative hypothesis $\mathrm{H}_{1}$ (there is a difference in the mean efficiency scores).

The significance and direction of the explanatory variables (extraction method and log processing location) on harvesting performance were estimated by regressing them on the estimated efficiency scores being the dependent variable. Tobit regression model is used to estimate the influence of the possible explanatory variables on the estimated efficiency scores and to identify the direction of the influence. Tobit regression is widely used in DEA studies to estimate the dependence of efficiency scores on environmental variables (Lawrence and Erwin, 2003; Oukil et al., 2016; Obi and Visser, 2017a).

\section{Results and Discussion}

\subsection{Summary Data on DMUs and Production Factors}

Performance estimation carried out in this study was based on a total of 1330 completed forest harvesting operations, gathered over a 10-year period (2009 - 2018). Individual completed harvests represent decision-making units in the DEA model. Details of the number of DMUs across the three operating environment difficulty categories shows that the medium category has the highest percentage of DMUs (49\%) across the entire study period while the hard category has the lowest percentage of DMUs (17\%). This reflects the predominance of plantation forest operating environment in New Zealand offering relatively medium difficulty to timber harvesting operations. Easy operating environment accounted for $34 \%$ of the total operating environment categories.

Summary statistics of the production factors (inputs and output) utilized in the categorical DEA production technology is presented in Table 1. The table presents the maximum, minimum, average and standard deviation for the production factors for the entire period of 2009-2018.

Table 1. Summary statistics of inputs and output

\begin{tabular}{lccccc}
\hline \multirow{2}{*}{ Year } & \multirow{2}{*}{ Statistics } & $\begin{array}{c}\text { Mech. } \\
\text { Index }\end{array}$ & $\begin{array}{c}\text { Harvest Area } \\
\text { Size (ha) }\end{array}$ & $\begin{array}{c}\text { Av. Piece } \\
\text { Size (tons) }\end{array}$ & System Productivity (tons/SMH) \\
\hline \multirow{2}{*}{2009 - 2018 } & Max. & 2.3 & 150.0 & 4.7 & 93.5 \\
& Min. & 0.2 & 1.0 & 0.3 & 5.2 \\
& Average & 0.7 & 18.9 & 2.0 & 29.3 \\
& SD & 0.3 & 18.5 & 0.7 & 12.4 \\
\hline
\end{tabular}

\subsection{Harvesting Performance Estimates}

The categorical DEA was computed with DEASolver software (Cooper et al., 2007). The performance estimates are presented in Table 2, sorted by individual groups of the operating environment difficulty categories - easy, medium and hard. As expected, the easy difficulty category has the highest mean harvesting efficiency of $55 \%$, followed by the hard at $51 \%$ efficiency score and then medium at $50 \%$. The mean efficiency score for easy harvesting difficulty category $(55 \%)$ is higher than the overall average for all operations in New Zealand estimated to be $52 \%$. This could be attributed to the relatively less challenging environment in which the operations were carried out. Although majority of the forest harvesting operations in New Zealand is characterised by the medium difficult operating environment, the harvesting operations in this group is estimated to have the lowest relative harvesting efficiency of 50\% (Table 2). This obviously impacted the overall harvesting efficiency of the sector over the study period considering that it is the predominant type of operating environment in New Zealand and represented the category with the lowest number of DMUs in the best practice frontier. This could mean that the harvesting systems deployed in medium difficulty operating environments may not have been fully optimized for productivity and efficiency.

Regarding the influence of difficulty of the operating environment on harvesting efficiency, the Kruskal-Wallis test is used to verify any significance of difference in the mean efficiency scores of the three categories of operating environment. The result shows that at least one of the mean efficiency scores is significantly different from the rest $(\mathrm{p}<0.000)$. Hence, the nature of the operating environment is an important determinant of forest harvesting efficiency. This is in line with earlier studies that reported significant influence of the operating environment variables on the performance of independent forest harvesting contractors (Obi and Visser, 2017a; Obi and Visser, 2018). 
Table 2. Efficiency scores by categorical groups

\begin{tabular}{|c|c|c|c|c|c|}
\hline \multirow{2}{*}{ Statistics } & \multicolumn{3}{|c|}{ Forest Harvesting } & \multirow{2}{*}{ Overall } & \multirow{2}{*}{$\begin{array}{l}\text { Standard } \\
\text { DEA VRS }\end{array}$} \\
\hline & Hard & Medium & Easy & & \\
\hline No. of DMUs & 230 & 650 & 450 & 1330 & 1330 \\
\hline Average efficiency score & 0.51 & 0.50 & 0.55 & 0.52 & 0.49 \\
\hline Standard Deviation & 0.20 & 0.16 & 0.20 & 0.19 & 0.19 \\
\hline Maximum score & 1.00 & 1.00 & 1.00 & 1.00 & 1.00 \\
\hline Minimum score & 0.11 & 0.15 & 0.09 & 0.09 & 0.10 \\
\hline DMUs on best practice frontier & 5 & 4 & 7 & 16 & 33 \\
\hline *Kruskal-Wallis test & & $0.000 * * *$ & & & \\
\hline
\end{tabular}

To further buttress the significance of the methodology applied in this study, the overall estimated mean harvesting efficiency presented in Table 2 is compared to the mean efficiency estimate obtained using the standard VRS DEA technique. The standard VRS DEA does not give consideration to the heterogeneity of the operating environment, hence the forest operations are assumed to operate in a homogenous environment without any categorization. The result obtained suggests an overestimation of harvesting efficiency of operations in the 'easy' operating environment. The number of DMUs in the efficient frontier moved up from 7 (obtained using the categorical DEA approach) to 18 amounting to about $61 \%$ increase. In total, the number of DMUs operating in the efficient frontier for all harvesting operations increased by $51 \%$ (from 16 to 33 DMUs) - this is a reflection of the overestimation of the performance of the harvest operations. Further, the mean harvesting efficiency of the operations in the 'hard' operating environment dropped from $51 \%$ (obtained based on the Categorical DEA approach) to $43 \%$. These DMUs were penalised for operating in the most challenging environment as their performance were measured against those in the easy and medium difficulty operating environment without any consideration for the heterogeneity of their environment. This result shows the significant importance of considering the operating environment of harvesting systems or methods when measuring productivity or efficiency.

\subsection{Breakdown of felling and extraction methods by the operating environment}

Table 3 shows a breakdown of the feeling and extraction methods deployed to the various operating environment categories offering different levels of difficulty. As expected for the easy operating environment, the predominant felling method is mechanized felling $(56 \%)$ which is higher than chainsaw felling by $12 \%$. Driven primarily by safety, mechanization of felling is one factor that changed significantly over the 10 -year period, whereby in $2009-2010$ only $23 \%$ was mechanized, compared to $77 \%$ in the last two years of the study (Visser, 2019).

The decision for selecting a method/technology at different phases of logging operation is determined by a number of factors including the site condition, cost of road construction, weather, available equipment and machines, skilled workers and applicable resource management strategy (Jaafari et al., 2015). The choice of chainsaw felling in easy operating environment in New Zealand could have been influenced by location and size of harvest area. For woodlot owners in New Zealand, aesthetics and protection of the environment are two of the top objectives during harvesting (Brown, 2018) as such the use of heavy equipment that disrupt the soil or contaminate water bodies could be unacceptable (Vokoun et al., 2006). On the part of the harvesting crews (loggers), cost of equipment move-in and lack of infrastructure could also influence the choice of chainsaw fellin

Table 3. Breakdown of timber felling and extraction methods used in different operating environment in New Zealand for the period 2009 - 2018.

\begin{tabular}{llccc}
\hline \multirow{2}{*}{ Method } & \multirow{2}{*}{ Category } & \multicolumn{3}{c}{ Operating Environment Difficulty Level } \\
\cline { 3 - 5 } & & Easy & Medium & Hard \\
\hline \multirow{2}{*}{ Felling method } & Chainsaw & $44 \%$ & $70 \%$ & $82 \%$ \\
& Mechanised & $56 \%$ & $30 \%$ & $18 \%$ \\
\hline \multirow{5}{*}{ Extraction method } & Cable Skidder & $3 \%$ & $1 \%$ & $1 \%$ \\
& Forwarder & $10 \%$ & $4 \%$ & $4 \%$ \\
& Grapple & $48 \%$ & $26 \%$ & $17 \%$ \\
& Skidder & & & \\
& Hauler & $13 \%$ & $32 \%$ & $44 \%$ \\
& Shovel & $4 \%$ & $1 \%$ & $3 \%$ \\
& Swing Yarder & $20 \%$ & $32 \%$ & $24 \%$ \\
& Tractor/Arch & $2 \%$ & $4 \%$ & $7 \%$ \\
\hline
\end{tabular}


The influence of lot size on the choice of felling method is reflected in the mean harvest area size for chainsaw felling in the easy operating environment in New Zealand plantation forest. The mean harvest area size that utilized chainsaw felling stood at 13.3 hectares while that of mechanized felling is 26 hectares. This means that on the average, for easy operating environment, mechanized felling is generally deployed to harvest area size of about 26.0 hectares. Although with manual felling (chainsaw) considerable value is lost from broken stems; labor turnover and shortage of skilled workers limit opportunities to develop harvesting practices that maximize value recovery (Raymond, 2012). For the extraction phase in easy operating environment, grapple skidder is the major extraction method utilized, accounting for $48 \%$ of all extraction operations (Table 3 ).

For the medium and hard operating environment categories, the predominant felling method is chainsaw; this method accounts for $70 \%$ and $82 \%$ of all tree felling activities in the medium and hard operating environment, respectively (Table 3 ). This is understandable as such environments are often characterized by steep (more than $35 \%$ ) and difficult to assess terrain; in addition to safety concerns with mechanized felling machines (Amishev and Evanson, 2010; Milne et al., 2013). In terms of extraction methods, hauler and swing yarder both share equal percentage usage of $32 \%$ for the medium difficulty operating environment; grapple skidder is next at $26 \%$ in terms of usage. For the hard difficulty operating environment, hauler is the predominant extraction method, accounting for $44 \%$ of all extraction operations.

For all forest harvesting operations, irrespective of the operating environment, grapple skidder is the predominant method of timber extraction in New Zealand, accounting for $32 \%$ of all timber extractions. This is in line with Harrill and Visser (2019) who in a survey of harvesting systems noted that for ground-based harvesting system in New Zealand, grapple skidders are the most common method of extraction accounting for about 35\% of extraction operations. Berkett (2012) noted that the dominant use of skidders is due to the preference for whole-tree harvesting wherein whole trees are extracted to the landing, processed and then loaded on trucks. Grapple skidder is closely followed by swing yarder $(29 \%)$ and hauler $(25 \%)$. Cable skidder appears to be the least used extraction method, accounting for just $1 \%$ of total extraction operations.

\subsection{Influence of log extraction method and processing location on harvesting performance}

The categorical DEA estimates of forest harvesting efficiency obtained in this study were sorted based on the extraction methods and $\log$ processing location associated with individual harvest operations. The result presented in Table 4 is for a total of 997 individual completed forest harvesting operations over the period 2011 - 2018.

Of the 997 individual harvest operations analysed, 3\% (30 DMUs) were identified to operate at the efficient or best practice frontier. About 33\% of the efficient DMUs utilized grapple skidder for extraction followed by forwarder and hauler accounting for about $20 \%$ and $16 \%$ of the DMUs on the best practice frontier, respectively. In addition, harvest operations that utilized grapple skidder for extraction has the highest mean forest harvesting efficiency score of 58\%; this is followed by DMUs that utilized forwarder for extraction at $56 \%$ mean efficiency score. Although cable skidder has low usage as indicated by the number of forest harvesting operations that utilized the method for extraction, DMUs that utilized it has a relatively high average harvesting efficiency of $51 \%$, higher than the average efficiency for harvest operations that utilized hauler $(47 \%)$, shovel (46\%), swing yarder (49\%), and tractor/arch (46\%). This result could mean that amongst all timber extraction methods, grapple skidder may be the most developed method in New Zealand.

Table 4. Harvesting efficiency scores on the basis of timber extraction method and processing site

\begin{tabular}{|c|c|c|c|c|c|c|c|}
\hline \multirow{2}{*}{ Factors } & \multirow{2}{*}{ Category } & \multirow{2}{*}{$\begin{array}{c}\% \text { of } \\
\text { DMUs }\end{array}$} & \multirow{2}{*}{$\begin{array}{c}\text { Best practice } \\
\text { units }\end{array}$} & \multicolumn{3}{|c|}{ Efficiency score } & \multirow{2}{*}{$\begin{array}{c}\text { Kruskal-Wallis } \\
\text { test }\end{array}$} \\
\hline & & & & Max. & Min. & Av. & \\
\hline \multirow{8}{*}{$\begin{array}{l}\text { Extraction } \\
\text { method }\end{array}$} & Cable Skidder & 1 & 0 & 0.81 & 0.19 & 0.51 & $0.000 * * *$ \\
\hline & Forwarder & 5 & 6 & 1.00 & 0.27 & 0.56 & \\
\hline & Grapple Skidder & 32 & 10 & 1.00 & 0.12 & 0.58 & \\
\hline & Hauler & 25 & 5 & 1.00 & 0.20 & 0.47 & \\
\hline & Shovel & 3 & 2 & 1.00 & 0.09 & 0.46 & \\
\hline & Swing Yarder & 29 & 4 & 1.00 & 0.21 & 0.49 & \\
\hline & Tractor/Arch & 5 & 3 & 1.00 & 0.21 & 0.46 & \\
\hline & Total & 100 & 30 & & & & \\
\hline \multirow{5}{*}{$\begin{array}{l}\text { Log } \\
\text { processing } \\
\text { site }\end{array}$} & At stump & 4 & 6 & 1.00 & 0.29 & 0.57 & 0.200 \\
\hline & Log Yard & 3 & 0 & 0.87 & 0.31 & 0.54 & \\
\hline & Primary landing & 88 & 24 & 1.00 & 0.09 & 0.52 & \\
\hline & Secondary landing & 5 & 0 & 0.95 & 0.21 & 0.48 & \\
\hline & Total & 100 & 30 & & & & \\
\hline
\end{tabular}

*** indicate significance at $\alpha=1 \%$. 
Kruskal-Wallis test shows a statistically significant difference $(p<0.000)$ in forest harvesting efficiency among the 7 different extraction methods (Table 4); at least one of the mean efficiency scores (the grapple skidder) is significantly different from others. This implies that the extraction method adopted in forest harvesting operations could significantly influence the estimated relative efficiency of the system. This further validates the earlier view by Jaafari et al. (2015) suggesting that the overall efficiency of timber harvesting depends heavily on the selection of an appropriate wood extraction method. It is essential to determine the productivity of applicable extraction methods and to optimise for various operational conditions, particularly for more difficult to operate sites with limited options.

In terms of log processing location, processing on primary landing is the predominant option for forest harvesting operations in New Zealand as it accounted for no less than $88 \%$ of total log processing on various sites. Other processing locations including at stump, log yard, and secondary landing shared a combined total of $12 \%$ of all $\log$ processing. Harvest operations with timber processing done at the stump has the highest harvesting efficiency of $57 \%$ followed by those with processing at $\log$ yard (54\%) and then primary landing (52\%). Harvest operations with processing at secondary landing has the lowest operational efficiency of $48 \%$ compared to others. The high harvesting efficiency scores estimated for processing at stump and log yard could have been influenced by their relatively low number of entries. Although, the mean harvesting efficiency estimated for the DMUs differ, the differences are not statistically significant (Table 4).

\subsection{Regression Analysis}

Regression analysis was carried out to estimate the relationship between the extraction methods and the estimated harvesting efficiency scores. Extraction technologies were represented using dummy variables $(1,0)$. The estimated regression result is shown in Table 5. Some of the timber extraction technologies negatively influenced harvesting efficiency including hauler, shovel, swing yarder, tractor/arch. However, cable skidder, forwarder, and grapple skidder positively influenced harvesting efficiency.

All cable-based timber extraction methods negatively influenced harvesting efficiency. Cable-based methods are the backbone of steep-slope timber harvesting and the transition from ground to cable-based timber harvesting usually happens at a slope of between $20-40 \%$ (Aalmo and Talbot, 2014; Bont and Heinimann, 2012). The mean terrain slope across New Zealand forest plantation has been on the increase from an average value of $11 \%$ in 2009 to $23 \%$ in 2018 with an overall average of $19 \%$ for the period $2009-2018$. The continued increase in terrain slope suggests that future extraction methods would mostly tend towards cable-based, although the introduction of winch-assist systems is significantly changing the level of mechanisation on steeper slopes. The negative influence the cable-based extraction methods could however be attributed to harvesting challenges associated with steep slope harvesting including soil bearing capacity, slope length, streams and drainage features, and surface unevenness (Davis and Reisinger, 1990). Continued effort at optimising cablebased extraction systems could pay off significantly for New Zealand forest harvesting sector in the near future.

Table 5. Regression estimates of harvesting efficiency vs. extraction methods

\begin{tabular}{ccc}
\hline Term & Coefficient & P-value \\
\hline Constant & 0.510 & 0.000 \\
Extraction technology & & \\
Forwarder & 0.023 & 0.718 \\
Grapple skidder & 0.074 & 0.211 \\
Hauler & -0.056 & 0.342 \\
Shovel & -0.074 & 0.276 \\
Swing yarder & -0.024 & 0.679 \\
Tractor/Arch & -0.073 & 0.243
\end{tabular}

All extraction methods $=0$, if cable skidder; forwarder $=1$, otherwise 0 ; grapple skidder $=1$, otherwise 0 ;

Hauler $=1$ otherwise 0 ; Shovel $=1$, otherwise 0 ; Swing yarder $=1$, otherwise 0 ; Tractor/Arch $=1$, otherwise 0 .

\section{Conclusions}

In this study, the relative efficiency of 1330 forest harvesting operations in New Zealand was measured using the categorical data envelopment analysis methodology, and the influence of timber extraction method and $\log$ processing location on harvesting efficiency were assessed. In the categorical DEA model, three inputs, one output and one categorical variable with three levels representing the levels of difficulty of the operating environment were used. The main findings are the following: (i) categorical DEA approach is an appropriate and robust technique in measuring the relative performance on forest harvesting operations as it is able to account for the heterogeneous nature of forest harvesting operating environment; (ii) the choice of log processing location does not significantly affect harvesting efficiency; (iii) timber extraction method is a factor that significantly influences the overall estimated performance of forest harvesting operation; and (iv) the nature of forest harvesting operating environment plays a significant role in the overall performance of the harvesting operation. 
These results provide guidance to industry analysts and decision makers on the importance of considering the operating environment when estimating harvesting efficiency or productivity of harvesting systems or methods.

\section{Acknowledgements}

We would like to thank Future Growers Research for their overall support of the Benchmarking system and the opportunity to complete this detailed analysis, as well as the many New Zealand forestry companies that regularly contribute to the Benchmarking System.

\section{Ethics Committee Approval: N/A.}

Peer-review: Externally peer-reviewed.

Author Contributions: Concept: O.F.O. and R.V.; Design: O.F.O. and R.V.; Supervision: R.V.; Resources: R.V.; Data Collection: R.V.; Analysis: O.F.O.; Literature Search: O.F.O.; Writing Manuscript: O.F.O. and R.V.; Critical Review: O.F.O. and R.V.

Conflict of Interest: The authors have no conflicts of interest to declare.

Financial Disclosure: The authors declared that this study has received no financial support

Cite this paper as: Obi, O.F., Visser, R., 2020. Estimating the Influence of Extraction Method and Processing Location on Forest Harvesting Efficiency - A Categorical DEA Approach. European Journal of Forest Engineering, 6(2): 60-68.

\section{References}

Aalmo, G.O., Talbot, B., 2014. Operator performance improvement through training in a controlled cable yarding study. International Journal of Forest Engineering, 25(1): 5-13.

Alam, M., Walsh, D., Strandgard, M., Brown, M., 2014. A log-by-log productivity analysis of two Valmet 475EX harvesters. International Journal of Forest Engineering, 25(1): 14-22.

Amishev, D., Evanson, T., 2010. Innovative methods for steep terrain harvesting. Proc. FORMEC, 2010: 1114.

Banker, R.D., Charnes, A., Cooper, W.W., 1984. Some models for estimating technical and scale inefficiencies in data envelopment analysis. Management Science, 30(9): 1078-1092.

Banker, R.D., Morey, R.C., 1986. The use of categorical variables in data envelopment analysis. Management Science 32(12): 1613-1627.

Bhutta, K.S., Huq, F., 1999. Benchmarking-best practices: an integrated approach. Benchmarking: An International Journal, 6(3): 254-268.
Bont, L., Heinimann, H.R., 2012. Optimum geometric layout of a single cable road. European Journal of Forest Research, 131(5): 1439-1448.

Brown, K., 2018. Harvesting woodlots in NZ: What do small-scale landowners and loggers think? Forest Engineering Conference April 16-19, 2018, Rotorua, New Zealand: 1-15.

Brown, M., Ghaffariyan, M. R., Berry, M., Acuna, M., Strandgard, M., Mitchell, R., 2020. The progression of forest operations technology and innovation. Australian Forestry, DOI: 10.1080/00049158.2020.1723044.

Charnes, A., Cooper, W.W., Rhodes, E., 1978. Measuring the efficiency of decision making units. European Journal of Operational Research, 2(6): 429-444.

Cook, W.D., Seiford, L.M., 2009. Data envelopment analysis (DEA)-Thirty years on. European Journal of Operational Research, 192(1): 1-17.

Cooper, W.W., Seiford, L.M., Tone, K., 2007. A Comprehensive Text with Models, Applications, References and DEA-Solver Software. Springer Science+ Business Media.

Daraio, C., Simar, L., 2007. Advanced Robust and Nonparametric Methods in Efficiency Analysis: Methodology and Applications. Springer Science \& Business Media.

Davis, C., Reisinger, T., 1990. Evaluating terrain for harvesting equipment selection. Journal of Forest Engineering, 2(1): 9-16.

Gerasimov, Y., Sokolov, A., 2014. Ergonomic evaluation and comparison of wood harvesting systems in Northwest Russia. Applied Ergonomics, 45(2): 318-338.

Ghaffariyan, M., Sessions, J., Brown, M., 2012. Machine productivity and residual harvesting residues associated with a cut-to-length harvest system in southern Tasmania. Southern Forests: a Journal of Forest Science, 74(4): 229-235.

Golany, B., Roll, Y., 1989. An application procedure for DEA. Omega, 17(3): 237-250.

Harrill, H., Visser, R., 2019. A survey of NZ groundbased harvesting systems. Forest Growers Research Harvesting, Rotorua, New Zealand, Harvesting Technical Note, 12(4): 1-7.

Harrison, J., Rouse, P., 2014. Competition and public high school performance. Socio-Economic Planning Sciences, 48(1): 10-19.

Harrison, J., Rouse, P., Armstrong, J., 2012. Categorical and continuous non-discretionary variables in data envelopment analysis: a comparison of two singlestage models. Journal of Productivity Analysis, 37(3): 261-276.

Jaafari, A., Najafi, A., Melón, M.G., 2015. Decisionmaking for the selection of a best wood extraction 
method: An analytic network process approach. Forest Policy and Economics, 50: 200-209.

Kruskal, W.H., Wallis, W.A., 1952. Use of Ranks in One-Criterion Variance Analysis. Journal of the American Statistical Association, 47(260): 583-621.

Kuah, C.T., Wong, K.Y., 2011. Efficiency assessment of universities through data envelopment analysis. Procedia Computer Science, 3: 499-506.

Kulak, D., Stańczykiewicz, A., Szewczyk, G., 2017. Productivity and time consumption of timber extraction with a grapple skidder in selected pine stands. Croatian Journal of Forest Engineering, 38(1): 55-63.

Lawrence, W., Erwin, T., 2003. Technical efficiency and service effectiveness for railways industry: DEA approaches. Journal of the Eastern Asia Society for Transportation Studies, 5(1): 2932-2947.

Lebel, L., 1998. Improving logging operations efficiency through benchmarking. Canadian Forest Industries, $1-4$

Lee, E., Han, S.-K., Im, S., 2019. Performance analysis of log extraction by a small shovel operation in steep forests of South Korea. Forests, 10(7): 585.

Marchi, E. Marchi, E., Chung, W., Visser, R., Abbas, D., Nordfjell, T., Mederski, P.S., McEwan, A., Brink, M., Laschi, A., et al., 2018. Sustainable Forest Operations (SFO): A new paradigm in a changing world and climate. Science of the Total Environment, 634: 13851397.

Milne, B., Chen, X., Hann, C., Parker, R., 2013. Robotisation of forestry harvesting in New ZealandAn overview. 10th IEEE International Conference on Control and Automation (ICCA). IEEE, pp. 16091614.

Muñiz, M., 2002. Separating managerial inefficiency and external conditions in data envelopment analysis. European Journal of Operational Research, 143(3): 625-643.

Murphy, G., Cown, D., 2015. Stand, stem and log segregation based on wood properties: A review. Scandinavian Journal of Forest Research, 30(8): 757-770.

Obi, O.F., Visser, R., 2017a. Influence of the operating environment on the technical efficiency of forest harvesting operations. International Journal of Forest Engineering, 28(3): 140-147.

Obi, O.F., Visser, R., 2017b. Operational efficiency analysis of New Zealand timber harvesting contractors using data envelopment analysis.
International Journal of Forest Engineering, 28(2): 85-93.

Obi, O.F., Visser, R., 2018. Including exogenous factors in the evaluation of harvesting crew technical efficiency using a multi-step data envelopment analysis procedure. Croatian Journal of Forest Engineering, 39(2): 153-162.

Oukil, A., Channouf, N., Al-Zaidi, A., 2016. Performance evaluation of the hotel industry in an emerging tourism destination: The case of Oman. Journal of Hospitality and Tourism Management, 29: 60-68.

Pajkoš, M., Klvač, R., Neruda, J., Kumar Mishra, P., 2018. Comparative time study of conventional cut-tolength and an integrated harvesting method-A case study. Forests, 9(4):194, doi:10.3390/f9040194

Raymond, K., 2012. Innovation to increase profitability of steep terrain harvesting in New Zealand. New Zealand Journal of Forestry, 57: 19-23.

Rönnqvist, M. D’Amours, S., Weintraub, A., Jofre, A., Gunn, E., Haight, R., Martell, D., Murray, A., T., Romero, C., 2015. Operations research challenges in forestry: 33 open problems. Annals of Operations Research, 232(1): 11-40.

Senturk, N., Ozturk, T., Demir, M., 2007. Productivity and costs in the course of timber transportation with the Koller K300 cable system in Turkey. Building and Environment, 42(5): 2107-2113.

Stokes, B.J., Schilling, A., 1997. Improved harvesting systems for wet sites. Forest Ecology and Management, 90(2-3): 155-160

Syrjänen, M.J., 2004. Non-discretionary and discretionary factors and scale in data envelopment analysis. European Journal of Operational Research, 158(1): 20-33.

Trzcianowska, M., LeBel, L., Beaudoin, D., 2019. Performance analysis of log yards using data envelopment analysis. International Journal of Forest Engineering, 30(2): 144-154.

Visser, R., 2009. Benchmarking Harvesting Cost and Productivity. Future Forests Research Ltd, Rotorua, New Zealand, Harvesting Technical Note, 2(6): 1-8.

Visser, R., 2019. A Decade of Benchmarking Harvesting Cost and Productivity. Forest Growers Research Harvesting, Rotorua, New Zealand, Harvesting Technical Note, 12(1): 1-4.

Vokoun, M., Amacher, G.S., Wear, D.N., 2006. Scale of harvesting by non-industrial private forest landowners. Journal of Forest Economics, 11(4): 223-244. 